\title{
Statin use does not protect from fractures: the healthy adherer effect is a plausible explanation in observational studies
}

\author{
A. Donzelli ${ }^{1}$ (I) A. Battaggia ${ }^{2} \cdot$ A. Schivalocchi $^{3}$
}

Received: 13 January 2017 / Accepted: 26 April 2017 / Published online: 29 May 2017

(C) The Author(s) 2017. This article is an open access publication

\section{Dear Editor,}

The conclusions of the recently published meta-analysis by An et al. [1], including 23 observational studies and 10 randomized controlled trials (RCTs), are as follows: "statin treatment may be associated with a decreased risk of overall and hip fractures, an increased BMD at the total hip, at the lumbar spine, and OC."

We disagree with these conclusions, for the following reasons.

First, observational studies are in any case prone to residual confounding, even when the reported data allow a careful control for many known or suspected confounders. So they may just suggest a hypothesis, needing appropriate RCTs for confirmation.

Unfortunately, the authors seem to overlook a powerful potential confounder, the "healthy-adherer" effect.

Ten years ago, a meta-analysis [2] of RCTs and cohort studies showed that a good adherence not only to drug therapy but also to placebo is associated with positive health outcomes, when compared to a poor adherence to both, placebo included. This supports the "healthy-adherer" effect, i.e., the

The views expressed are the first author's own and do not necessary represent the views of his organization.

A. Donzelli

adonzelli@ats-milano.it

1 Education to Appropriateness and EBM Area - ATS of the Metropolitan City of Milan, Milan, Italy

2 Foundation Allineare Sanità e Salute - c/o Studio Tracanella Via C.G. Merlo, 3 -, 20122 Milan, Italy

3 Resident in Hygiene, Public Health and Preventive Medicine, University of Milan-Bicocca, Milan, Italy adherence to drug therapy may be a surrogate marker for a general healthier behavior.

Famous RCTs showed better outcomes in groups with a good adherence to placebo, e.g., in WHI [3], comparing hormonal replacement therapy versus placebo in postmenopausal women, high-adherers in the placebo arm showed significant favorable outcomes, including fewer hip fractures (HR 0.50; 95\% CI $0.33-0.78$ ) and a decrease in mortality (HR 0.64; 0.51-0.80) [3], after adjusting for potential confounders. Moreover, low-adherers to placebo were more likely to show low adherence to statins and osteoporosis medications [3].

Likewise, in the Fracture Intervention Trial (FIT), comparing alendronate versus placebo, in the placebo arm highadherers showed substantial benefits compared to lowadherers [4].

Second, a compelling indirect evidence of such confounder comes from a prospective cohort study of statin patients using data from British Columbia [5]. In this study, after multivariable-adjustment, high-adherers were less likely than lowadherers to have not only myocardial infarction but also accidents. This effect was greatest for motor-vehicle accidents (HR 0.75; 0.72-0.79) and workplace accidents, but was also significant for burns, falls, fractures, open wounds, poisoning.... Other unexpected protective associations were dental problems, drugs dependency, food-borne bacterial infections, and gout. Conversely, high-adherers used more screening services.

This study strongly supports the hypothesis that highadherers to statins show healthier behaviors than comparable less-adherent patients.

Therefore, controlling for known/supposed confounders does not guarantee to consider the unknown or less documented ones and it cannot account for psychological factors, such as attitudes toward the prescribed therapy, or the belief in its effectiveness. 
Third, RCTs only, and not observational studies, are designed to prove causality. Figure 2 [1] ("cohort studies OR for statins and fracture risk") includes also the only two RCTs [6, 7], where the pooled RR is 1.004. Figure 3 [1] (BMD at total hip, lumbar spine, and femoral neck) separates the two RCTs [8, 9], and their pooled Std. mean difference are not significant and around zero. Figure 4 [1] also separates the RCTs: their pool shows a borderline significance favoring statins for OC, and non-significant Std. mean difference for BALP and S-CTX.

Thus, statins do not seem to protect from fractures; the observational studies' results may have simple alternative explanations.

\section{Compliance with ethical standards}

\section{Conflicts of interest None.}

Open Access This article is distributed under the terms of the Creative Commons Attribution-NonCommercial 4.0 International License (http:// creativecommons.org/licenses/by-nc/4.0/), which permits any noncommercial use, distribution, and reproduction in any medium, provided you give appropriate credit to the original author(s) and the source, provide a link to the Creative Commons license, and indicate if changes were made.

\section{References}

1. An T, Hao J, Sun S, Li R, Yang M, Cheng G, Zou M. Efficacy of statins for osteoporosis: a systematic review and meta-analysis. Osteoporos Int 28:47-57. doi:10.1007/s00198-016-3844-8
2. Simpson SH, Eurich DT, Majumdar SR, Padwal RS, Tsuyuki RT, Varney $\mathrm{J}$ et al (2006) A meta-analysis of the association between adherence to drug therapy and mortality. BMJ 333(7557): 15

3. Curtis JR, Larson JC, Delzell E et al (2011) Placebo adherence, clinical outcomes, and mortality in the women's health initiative randomized hormone therapy trials. Med Care 49(5): 427-435

4. Curtis JR, Delzell E, Chen L, Brookhart MA, Cadarette SM, Chlebowski R et al (2011) The relationship between bisphosphonate adherence and fracture: is it the behavior or the medication? Results from the placebo arm of the fracture intervention trial. J Bone Miner Res 26(4):683-688

5. Dormuth CR, Patrick AR, Shrank WH, Wright JM, Glynn RJ, Sutherland J et al (2009) Statin adherence and risk of accidents: a cautionary tale. Circulation 119(15):2051-2057

6. Reid IR, Hague W, Emberson J, Baker J, Tonkin A, Hunt D et al (2001) Effect of pravastatin on frequency of fracture in the LIPID study: secondary analysis of a randomised controlled trial. Longterm Intervention with Pravastatin in Ischaemic Disease 357(9255): 509-512

7. Peña JM, Aspberg S, MacFadyen J, Glynn RJ, Solomon DH, Ridker PM (2015) Statin therapy and risk of fracture: results from the JUPITER randomized clinical trial. JAMA Intern Med 175(2):171177

8. Chen ZG, Cai HJ, Jin X, Lu JH, Wang J, Fang NY (2014) Effects of atorvastatin on bone mineral density (BMD) and bone metabolism in elderly males with osteopenia and mild dyslipidemia: a 1-year randomized trial. Arch Gerontol Geriatr 59(3):515-521

9. Rejnmark L, Buus NH, Vestergaard P, Heickendorff L, Andreasen F, Larsen ML et al (2004) Effects of simvastatin on bone turnover and BMD: a 1-year randomized controlled trial in postmenopausal osteopenic women. J Bone Miner Res 19(5):737-744 